\title{
線形時変解析的システムの可制御性 $\dagger$
}

\author{
久 永 公 紀*・高 橋 進 一* \\ Controllability in Linear Time-Varying Analytic Systems \\ Kiminori Hisanaga* and Shin-ichi TaKahashi*
}

\section{1. まえがき}

線形時変解析的システムとは, 状態方程式における 各係数行列の要素が解析関数であるような線形時変シ ステムのことである。てのシステムに関する構造解析 の重要性は, 多くの線形時変システムがこのシステム に含まれ，または近似可能である点に存する. 線形時 変解析的システムの可制御性についてはすでにいくつ かの研究 ${ }^{1,22}$ があるが，本文では可制御部分空間の概 念を導入し,より詳細かつ統一的にその性質を検討す る.

\section{2. 対象とするシステム}

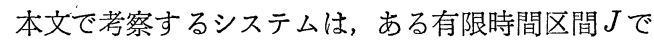
定義された状態方程式

$$
\begin{aligned}
& \frac{d}{d t} x(t)=A(t) x(t)+B(t) u(t) \\
& y(t)=C(t) x(t)
\end{aligned}
$$

で記述される線形時変解析的システムとする．乙てに $x(t), u(t), y(t)$ はそれぞれ状態, 入力, 出力ベクトル を表わし, $A(t), B(t), C(t)$ は解析関数を要素とする関 数行列である.なお，ててでいう解析関数とは，定義 された区間 $J$ 内の任意の点に拝いてテイラー級数に展 開可能な関数のことである. また，以後現れるすべて の時刻は区間 $J$ 内の時刻とする.

初期状態 $x\left(t_{0}\right)=x_{0}$ に対する微分方程式 (1 a ) の解 は,

$$
x(t)=\Phi\left(t, t_{0}\right) x_{0}+\int_{t_{0}}^{t} \Phi(t, \tau) B(\tau) u(\tau) d \tau
$$

で与えられる. ことに， $\Phi(t, \tau)$ は行列微分方程式

†第 25 回自動制御連合講演会で発表 (昭 $57 \cdot 11$ )

* 慶応義塾大学理工学部 横浜市港北区日吉 3-14-1

* Faculty of Science and Engineering, Keio University, Yokohama (Received April 20, 1983) (Revised June 6, 1983)

Keyword: linear time-varying analytic systems, controllability, controllable subspace

$$
\frac{d}{d t} \Phi(t, \tau)=A(t) \Phi(t, \tau), \Phi(\tau, \tau)=I
$$

の解として定義される状態遷移行列であり，つぎの

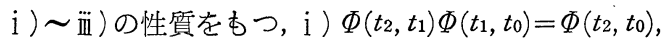
ii ) $\Phi^{-1}\left(t_{1}, t_{0}\right)=\Phi\left(t_{0}, t_{1}\right)$, iii $)^{2)} A(t)$ の要素が解析関数な らば, $\Phi(t, \tau)$ の要素す解析関数である.

なお，可制御性の定義については文献 3$)$ を参照さ れたい.

\section{3. 可制御性に関する考察}

従来, 線形時変解析的システムを含む一般の線形時 変システムの可制御性の判定条件としては，つぎの命 題が基本である.

[命題] ${ }^{4)}$ (1) 式のシステムに扔いて, 時刻 $t_{0}$ で状 態 $x_{0}$ が可制御であるための必要十分条件は， $x_{0} \in \mathrm{I}_{\mathrm{m}}$ $\left[W\left(t_{0}, t_{1}\right)\right]$ となるような時刻 $t_{1}\left(>t_{0}\right)$ が存在すること である. ここに $W\left(t_{0}, t_{1}\right)$ は, 次式で定義される可制 御性のグラム行列である.

$$
\begin{gathered}
W\left(t_{0}, t_{1}\right)=\int_{t_{0}}^{t_{1}} \Phi\left(t_{0}, t\right) B(t) B^{\prime}(t) \Phi^{\prime}\left(t_{0}, t\right) d t \\
(\text { ' は転置を表わす) }
\end{gathered}
$$

Remark 1: $x\left(t_{0}\right) \in \mathrm{I}_{\mathrm{m}}\left[W\left(t_{0}, t_{1}\right)\right]$ ならば, $x\left(t_{1}\right)=0$ とすることができるような適当な入力が存在する ${ }^{4)}$.

この命題では，状態遷移行列などより作られるグラ ム行列の性質により判定条件を与えている. しかしな がら，(3)式の行列微分方程式の解である状態遷移行 列を求めることは一般に困難である. そこで本文で は, 時不変系における可制御部分空間5)を線形時変解 析的システムに拡張し, 状態遷移行列を求めることな く(1)式システムの可制御性を判定する方法を提案す る.

【定義】次式で定義される $\Psi(s)$ を， $(A(t), B(t))$ の 時刻 $s$ 亿おける可制御部分空間という.

$$
\Psi(s)=\sum_{i=1}^{\infty} \operatorname{Im}\left[\left.\left(A(t)-\frac{d}{d t}\right)^{i-1} B(t)\right|_{t=s}\right]
$$

可制御部分空間について，つぎの補題が成り立つ.

[補題 1] $t_{1}>t_{0}$ なる任意の時刻 $t_{0}, t_{1} に$ 対して次 
式が成立する.

$$
\Psi\left(t_{0}\right)=\operatorname{Im}\left[W\left(t_{0}, t_{1}\right)\right]
$$

(証明) $W\left(t_{0}, t_{1}\right)$ は対称行列だから，(6)式は次式 と等価である.

$$
\left(\Psi\left(t_{0}\right)\right)^{\perp}=\mathrm{K}_{\mathrm{er}}\left[W\left(t_{0}, t_{1}\right)\right]
$$

$\left((\cdot)^{\perp}\right.$ は部分空間・の直交補空間を表わす)

あし， $x \in \mathrm{K}_{\mathrm{er}}\left[W\left(t_{0}, t_{1}\right)\right]$ ならば,

$$
x^{\prime} W\left(t_{0}, t_{1}\right) x=\int_{t_{1}}^{t_{0}}\left|B^{\prime}(t) \Phi^{\prime}\left(t_{0}, t\right) x\right|^{2} d t=0
$$

である.よって次式を得る.

$$
x^{\prime} \Phi\left(t_{0}, t\right) B(t)=0 \quad\left(t_{0} \leqq t \leqq t_{1}\right)
$$

$d \Phi\left(t_{0}, t\right) / d t=-\Phi\left(t_{0}, t\right) A(t)$ であることを用いると， (9) 式を $t=t_{0}$ でつぎつぎと微分すれば $i=1,2, \cdots$, に対し

$$
x^{\prime}\left(\left.\left(A(t)-\frac{d}{d t}\right)^{i-1} B(t)\right|_{t=t_{0}}\right)=0
$$

を得る. 式(10)より

$$
\begin{aligned}
x & \in \bigcap_{i=1}^{\infty}\left(\operatorname{Im}\left[\left.\left(A(t)-\frac{d}{d t}\right)^{i-1} B(t)\right|_{t=t_{0}}\right]\right)^{\perp} \\
& =\left(\sum_{i=1}^{\infty} \operatorname{Im}\left[\left.\left(A(t)-\frac{d}{d t}\right)^{i-1} B(t)\right|_{t=t_{0}}\right]\right)^{\perp} \\
& =\left(\Psi\left(t_{0}\right)\right)^{\perp}
\end{aligned}
$$

となり次式が得られる.

$$
\mathrm{K}_{\mathrm{er}}\left[W\left(t_{0}, t_{1}\right)\right] \subset\left(\Psi\left(t_{0}\right)\right)^{\perp}
$$

あし， $x \in\left(\Psi\left(t_{0}\right)\right)^{\perp}$ ならば上のステップを逆にたどり (11) 式より (10)式を得る. ところで解析関数は, 定義

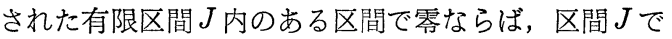
零に等しい之いう性質をあつ. よって $x^{\prime} \Phi\left(t_{0}, t\right) B(t)$ を $t=t_{0}$ でテイラー級数に展開したときの第 $i$ 項が

$$
\frac{1}{(i-1) !} x^{\prime}\left(\left.\left(A(t)-\frac{d}{d t}\right)^{i-1} B(t)\right|_{t=t_{0}}\right)\left(t-t_{0}\right)^{i-1}
$$

であるととと $(10)$ 式より(9)式が導びかれる（9)式 より(8)式が得られ，W(to, $\left.t_{1}\right)$ は準正定值行列だか ら, $x \in \mathrm{K}_{\mathrm{er}}\left[W\left(t_{0}, t_{1}\right)\right]$ となる. ゆえに

$$
\left(\Psi\left(t_{0}\right)\right)^{\perp} \subset \mathrm{K}_{\mathrm{er}}\left[W\left(t_{0}, t_{1}\right)\right]
$$

であり，(12)，(13)式より（7)式すなわち（6)式が成 立するととが証明された。

[補題 2] 任意の時刻 $t_{0}, t_{1}$ に対し次式が成立する.

$$
\Psi\left(t_{0}\right)=\Phi\left(t_{0}, t_{1}\right) \Psi\left(t_{1}\right)
$$

（証明）補題 1 の証明より， $x^{\prime} \Phi\left(t_{0}, t\right) B(t)=0$ は $x \in\left(\Psi\left(t_{0}\right)\right)^{\perp}$ と等価である. また， $t=t_{1}$ でつぎつぎと 微分することにより, $x^{\prime} \Phi\left(t_{0}, t\right) B(t)=0$ は $x \in\left(\Phi\left(t_{0}\right.\right.$, $\left.\left.t_{1}\right) \Psi\left(t_{1}\right)\right)^{\perp}$ と等価であることあ同様に示すととができ る. よって, $\Psi\left(t_{0}\right)=\Phi\left(t_{0}, t_{1}\right) \Psi\left(t_{1}\right)$ である.

これらの命題および補題より，つぎの定理を得る。
《定理 1》（1)式のシステムにおいて，時刻 $t_{0}$ で 状態 $x_{0}$ が可制御であるための必要十分条件は， $x_{0} \in$ $\Psi\left(t_{0}\right)$ となることである.

《定理 2》（1)式のシステムが可制御であるための 必要十分条件は，ある任意の時刻 $t_{0}$ に拈いて $\left(\Psi\left(t_{0}\right)\right)^{\perp}$ =0 となることである.

(定理 1 と 2 の証明) 命題と補題より明らか.

Remark 2: 定理 1 で与えたある時刻でのある状態 の可制御性の判定条件は，文献 1)，2）の可制御行列に よる解析方法では扱えなかった問題である．また定理 2 は文献 1) の条件と比べて, 定義された時間区間内 の任意の一点において判定可能であるという特徵をも ว.

以上の議論より, 線形時変解析的システムはつぎの 性質を有する．ただし，性質 iii) は文献 1)であ指適 されている。

i ) $x\left(t_{0}\right) \in \Psi\left(t_{0}\right)$ ならば, 任意の $\delta>0\left(t_{0}+\delta \in J\right)$ に 対して $x\left(t_{0}+\delta\right)=0$ とするてとができるような適 当な入力が存在する.

ii ) 時刻 $t$ における可制御な状態の張る部分空間の 次元，すなわち $\mathrm{d}_{\mathrm{im}}\{\Psi(t)\}$ は， $t$ の值にかかわら ず一定である。

iiii) システムがある時刻で可制御であるととと，シ ステムが可制御であることは等価である.

\section{4. あとがき}

可制御部分空間の概念を通して, 線形時変解析的シ ステムの可制御性に関する統一的な考察を行った. 可 観測性については， $(C(t), A(t))$ の時刻 $s$ における不 可観測部分空間 $\Theta(s)$ を

$$
\Theta(s)=\bigcap_{i=1}^{\infty} \mathrm{K}_{\mathrm{er}}\left[\left(\left.\left(A^{\prime}(t)+\frac{d}{d t}\right)^{i-1} C^{\prime}(t)\right|_{t=s}\right)^{\prime}\right]
$$

と定義するととにより，本文と同様理論展開が可能で ある。

\section{参 考 文 献}

1) L. M. Silverman and H. E. Meadows: Controllability and Observability in Time-Variable Linear Systems, SIAM J. on Control, 5-1, 64/73(1967)

2) A. Chang: An Algebraic Characterization of Controllability, IEEE Trans. on Automatic Control, AC-10-1, 112/113(1965)

3) 有本 卓: 線形システム理論, 83/86, 産業図書(1974)

4) R. W. Brocket : Finite Dimensional Linear Systems, 74/91, Wiley (1970)

5) W. M. Wonham: Linear Multivariable Control: A Geometric Approach, 2 nd ed., Springer-Verlag, N. Y. (1979) 